\title{
A COMMUNITY BASED HEALTH PROMOTION INTERVENTION IN CHANGING THE ATTRACTIVE IMAGE ON ALCOHOL AMONG STUDENTS IN A GOVERNMENT SCHOOL IN NORTH CENTRAL PROVINCE, SRI LANKA
}

\author{
Sujith Jayarathna $^{1 *}$, Manoj Fernando ${ }^{2}$, Thilini Herath ${ }^{3}$ and Duminda Guruge ${ }^{2}$ \\ ${ }^{1}$ National Child Protection Authority, Sri Lanka \\ ${ }^{2}$ Rajarata University of Sri Lanka, Sri Lanka \\ ${ }^{3}$ Eastern University, Sri Lanka, Sri Lanka
}

\begin{abstract}
In Sri Lanka, the main occupation of the alcohol users was students according to the International Standard Classification of Occupation. Attractiveness of the image of alcohol is one of the key determinants and this image develops through peer norms. Aim of the study was to assess the effectiveness of a health promotion intervention in changing the attractive image of alcohol among students. A quasi experimental study was conducted among students from grade 8 to 11 from two schools in Anuradhapura and Polonnaruwa districts in Sri Lanka as the intervention and control group respectively. Intervention was delivered through a group of voluntary students from grade 11 with training to challenge peer norms. Data were collected using self-administered questionnaires and the chi square test was performed by SPSS. Acceptance on 7 out of 10 norms towards alcohol were significantly reduced in the intervention group with a p value $<0.05$ (95 CI level) by comparing post evaluation results in the intervention group with the post evaluation results in the control group according to the chi square test. A health promotion intervention consists of a trained student group is effective in challenging peer norms for reducing the attractive image of alcohol among students.
\end{abstract}

Keywords: Attractive image on alcohol, peer norms, students, Sri Lanka

\section{Introduction}

Globally, alcohol is a leading public health problem (Mokdad et al, 2013, Rehm et al, 2009, World Health Organization (WHO), 2004). According to the research, various patterns of alcohol consumption is prevalent throughout the world (Jernigan, 2001) and it results in multiple diseases, risk conditions and also a threat to a health system of a country (Conway, 2005, Mokdad et al, 2013). Alcohol is one of the largest avoidable risk factors as it contributes by $4 \%$ to the total mortality and by $4 \%$ to $5 \%$ to the disability-adjusted life-years (Rehm et al, 2009). Further according to the research, there is a strong relationship between economic wealth and alcohol consumption in low-income countries and further, poor populations and countries have a greater disease burden than high-income populations and countries (Grant and Dawson, 1997, Rehm et al, 2009, Whitefor, 2013)

According to the past studies initiation and continuation of alcohol consumption guide by a multifactorial phenomenon (Samarasinghe, 2006a, Yan et. al, 2008) and the behavior of consuming alcohol is determined by factors such as portraying alcohol as an attractive commodity, privileges given to alcohol use, lack of knowledge about 'real' harm and unavailability of effective policies. Further, the role of knowledge in determining alcohol consumption is having a less importance than the role of other factors mentioned (Samarasinghe, 2006a). Researchers have highlighted the attractiveness of the image of alcohol as one of the front line factors (Samarasinghe et al, 1987) in determining once decision of consuming alcohol. In addition to it, alcohol industry is designing their strategies targeting these factors and they advertise alcohol as an attractive commodity especially to the category of adolescents in which students are also fall in. (Jackson et al, 2000). Similarly, students also learn alcohol as an attractive behavior by observing peers and elder counterparts who 
consume alcohol (Hawkins et.al, 1992, Samarasinghe, 2006b). So, the perception of alcohol as an attractive commodity is a learnt behavior and has important implications in measures on reversing the attractive image on alcohol (Velleman, 2009).

Accurate data, regarding alcohol consumption in Sri Lanka is scarce (De Silva et al, 2009). However, available literature pointed out that the prevalence of alcohol consumption among males was $39.6 \%$ and among females it was $2.4 \%$ (Somatunga et. al, 2014). Moreover, according to a study, the majority of alcohol user's (17.5\%) main occupation was a student when analyzed its study sample's occupations according to the International Standard Classification of Occupations and further, Sri Lankan adolescents tend to initiate alcohol experience at 16-20 ages (Alcohol and Drug Information Centre, 2010). Similarly, literature also pointed out that the school is a most important setting to conduct interventions for adolescents to delay their age of initiation because peer norms appear to be critical in shaping adolescent involvement with alcohol (Borsari and Carey, 2001) and these peer norms are determined by several factors; where the attractive image of alcohol plays a great deal (Perera and Torabi, 2009). Attractive image of alcohol is a combination of notions which in general can be described as perceiving alcohol consumption as a normal and acceptable deed. Apart from this, linking alcohol with pleasurable incidents of life, excuses given to the behaviors conducted by the drunken people and considering alcohol as a mean of becoming a reputed, fashionable adult are also considered as indicators of attractive image on alcohol (Samarasinghe, 2006b).

Global studies on alcohol prevention consists of individual interventions, family and school programs, social network interventions and community mobilization (Carey et al, 2007, Derges et al, 2017, Harachi et al, 1996, Spoth et al, 2002, Valente et al,2007). Even though, alcohol is an arising public health epidemic in Sri Lanka, there is a dearth of scientific evidence on the effective interventions including the interventions which can be implemented via the Health Promotion Approach (HPA) (WHO, 2009) in changing attractive image on alcohol. HPA is introduced at the first international conference on health promotion held in Ottawa and it empowers communities to achieve health goals rather not relying on the expert guidelines. So, the absence of this information will affect the ability to take locally relevant preventive measures to reduce the alcohol problem. Thus this study was designed as a pilot study to assess the effectiveness of a health promotion intervention on changing attractive image on alcohol among students in grade 8 to 11 (13-16 years of age) in a state school in Sri Lanka.

\section{Material and methods}

\section{Setting}

This study was conducted by using quasi experimental design from May 2011 to July 2012. Two schools from the Anuradhapura and Polonnaruwa districts in Sri Lanka were selected as an intervention and control groups. Educational Divisions (ED) were used to select two schools by means of similar socioeconomic background but with an approximate distance. Sangilikanadarawa Maha Vidyalaya, the intervention school situated in the Rambewa ED and Orubedi Siyambalawa Vidyalaya, the control school situated in the Elahera ED. Intervention process was carried out for a period of approximately six months from January, 2012 to July, 2012.

\section{Participants}

Study population was all the students in grade 8-11 (during the year 2012) in the selected EDs.

\section{Sample size and sampling method}

All eligible schools in both EDs were listed according to the alphabetical order by using names of the school. Eligible schools were selected according to the inclusion criteria 1) school which has classes above grade 9 (In Sri Lanka School grades are from grade 1 to grade 13) and 2) supportiveness of the principle. And exclusion criteria included 1) a school which was participated to alcohol prevention program within last 6 months prior to 
the intervention and 2) a school which have classes above grade 11(Normally in Sri Lanka, time table schedule is tough for students above grade 11 as they are in touch with a major cutoff exam in Sri Lanka. So to avoid difficulties in arranging time slots these classes were excluded). Simple random sampling was used to select a school from all eligible schools from both intervention and control areas.

Both male \& female students were considered as study subjects. Names of the students in grade 8 to 11 were obtained through the school registries and were arranged according to the alphabetical order. Random numbers were generated to recruit the sample. Ninety students from each intervention and control group were selected through simple random sampling method.

\section{Intervention development}

Key Informant Interviews (KII) was conducted with experts in the field of Health Promotion (HP) and alcohol prevention in Sri Lanka. Experts involved are academics those who have prior experience on alcohol prevention work and program managers of Non-Governmental Organizations who work for same targets. These KII were about prevalent norms among students, structure of an effective intervention targets on norms and the logical order of changes among students after a HP intervention. By considering the KII, a Logical Frame Work (LFW) (Figure 1) which describes logical order of intended results was developed by the Principal Investigator (PI).The main goal of the study was to assess the effectiveness of the developed HP intervention. Ten social norms (Figure 2) were selected to address through an expert committee meeting. Specific objectives were to (a) describe the pre prevalence of attractive image on alcohol among students (b) implement a plan to change the selected social norms among students and (c) evaluate the effects of the intervention in terms of changes in the attractive image among students.

\section{Theoretical back ground of the intervention}

Intervention was designed according to the principals of the HPA (Samarasinghe et al, 2011) such as empowering students, addressing Underlying Community Factors (UCF), conducting in a community based manner, conducting as a process apart from single activities over time and measuring the process and the intended changes. Primary focus of the intervention was to change the acceptance on social norms which create an attractive image on alcohol by empowering students. To achieve this, UCF of continuation of social norms should be addressed. UCF should be clarified for the setting by its own members (Peris et al, 2013). UCF for this study were identified by conducting a Focus Group Discussion (FGD) with students and the identified UCF were, attractive image of the adjacent social network, the autonomy given to an individual student by his or her group / acceptance given by the peer group to discuss about the reality about alcohol and lack of skills to deal with the respective norms.

\section{Intervention structure and delivery}

Intervention activities were carried out with grade 11 students by PI with an average of at least two meetings per month. Intervention was targeted to build a mechanism among the students to question the selected ten norms on attractive image on alcohol. Intervention activities were included 1) interactive discussions to analyze community scenarios on norms on alcohol and 2) role plays to increase skills. In role plays students were trained to change the norms according to a mutually agreed common mechanism. Content of the mechanism included 1) measures to disseminate the intervention for other grades 2) Methods to follow up the changes and obstacles. Suggested measures for dissemination of the intervention were informal discussions in common places, hanging influential posters which addresses social norms and public speaking in school assembly. Simultaneously with the intervention activities students were motivated to measure the intended changes and the process by keeping ongoing records.

\section{Study instruments}


A pre-tested validated Self Administrated Questionnaire (SAQ) which is developed to suit to the Sri Lankan context by referring to past literature on prevalent social norms was used as the study instrument. Content and consensual validity was determined using a delphi process, where experts in the field (two academics work on community based alcohol prevention and an officer from a Non-Governmental Organization work on alcohol prevention) involved. For content validity, the experts rated for each identified norm on a scale of 10 (high influence on students in Sri Lanka) to 0 (low influence on students in Sri Lanka). For consensual validity, the experts rated again on a scale of 10 (more appropriate to use with grade 8 to 11 students in Sri Lanka) to 0 (less appropriate to use with grade 8 to 11 students in Sri Lanka. These ratings were summarized and ten norms were selected as most relevant norms to include in the questionnaire. Reliability was determined by test-retest reliability method and the questionnaire was administered before and after a 14- day period to a same group of students similar to the original study sample.

Final instrument consisted of ten social norms on attractive image on alcohol. For each norm participants could respond for a five point likert type scale ranging from totally agree, agree, can't say, disagree and to totally disagree.

\section{Data Collection}

The data were collected from grade 8-11 students in both intervention and control groups at the schools by the PI during both pre and post evaluations to obtain socio economic and demographic data and the level of acceptance on each selected norm. The principals of the schools were informed about the purpose of the study and prior notice was given before visiting to the schools and two attempts were taken if a student was unable to meet. A pretest was conducted before collecting data.

\section{Data analysis}

The characteristics of the study sample was summarized and described by using descriptive statics and the comparison of the characteristics of intervention and control groups were done using Chi square test. Similarly, chi square test was used to detect the statistical significance difference among pre and post levels of prevalence of attractive image in intervention and control group. Statistical Package of Social Sciences (SPSS) 20 statistical software was used to analyze the quantitative data.

\section{Ethical considerations}

Ethical approval for conducting the study was granted from the ethics review committee of the Faculty of Medicine and Allied Sciences, Rajarata University of Sri Lanka. Informed written consent for collecting data and to publish findings was obtained from care givers of the selected students prior to data collection. Standard measures were taken to ensure confidentiality of data. PI collected the data and a unique serial number was assigned to each data.

Community scenarios were used as a strategy to discuss about the topic alcohol with students, to minimize the discomfort occurred by discussing about alcohol directly. All the interventional activities were designed through group discussions and students were trained specially on effective communication skills. This was aided them to avoid possible bullying events because of the intervention activities. Data collection was conducted in the school premises. Data collection conducted grade wise and all the recruited students were requested to attend to one class room belong to their grade, after the school. Students were informed to fill the questionnaire by their own and data collectors supervised the process. Students were linked with experts and services whom they can get help if they sought to solve any matter related to alcohol consumption. Such students were monitored by the PI throughout the project for necessary services. An intervention program was offered to the control community at the end of the study.

\section{Results}


Response rate within the study population was $100 \%$. All students from the intervention and control groups were included in the data analysis.

\section{Student's basic socioeconomic and demographic data}

Both intervention and control groups consisted with more males 50 (44.4\%) and 55 (61.1\%) respectively. According to the Table 1, in the intervention group most of the students (46.7\%) are from farming families and in the control group it was $56.7 \%$. According to the statistical test, there was no statistical significant difference between the control and intervention groups in relation to socio demographic details.

\section{Attractive image among students in pre evaluation}

Majority of the participants in both groups have a same level of prevalence of attractive image on alcohol. There was no significant difference in student's acceptance of norms on attractive image in the both intervention and control areas (Table 2)

\section{Changes in prevalence of attractive image among students in post evaluation-Intervention group}

Seven out of ten selected norms showed a significant change of acceptance during the pre and post interventional comparison. The image of three norms "By using alcohol can engage with the new fashion", "Alcohol is a good way to show rebelliousness" and "It is easy to threat other under the influence of alcohol" only slightly change and that changes were not significant (Table 3).

\section{Changes in prevalence of attractive image among students in post evaluation-Control group}

According to the data there were no changes to the acceptance of selected norms among students in the control group during study period (Table 4).

\section{Changes in prevalence of attractive image among students in post evaluation- Intervention and control group}

Significant differences were noted between the proportions of students from interventional and control groups who accepted selected norms in the post-evaluation. Such changes were not observed for only two norms (Table 5).

\section{Discussion}

Our findings indicate that the HP intervention developed for this study has successfully changed the acceptance of attractive image on alcohol among 13 to 16 years of age students in a state school in Sri Lanka. At pretest acceptance on selected social norms among students were high. At posttest participants in intervention group showed less acceptance on most of the social norms (7 out of 10) whereas no similar change observed in the control group. This study measured the acceptance on prominent social norms that are said to 'trigger' initiation of alcohol which were identified though KII in Sri Lanka and these norms represent strong beliefs on alcohol. According to results, these norms are highly prevalent among students and also an indication of the typical thinking pattern of Sri Lankan students on alcohol. But due to the paucity of past research evidence about norms we couldn't compare the findings within Sri Lanka.

This study is not in line with other previous interventional studies in the globe as most of the past studies have been focused on psychological theories and targeted on developing knowledge on alcohol related harm (Perry et al, 1996), however, these studies also reported reduction in consumption among their targeted groups. In contrast, this study is an intervention to reverse what already learnt and also a peer teaching intervention. Peer teaching is more effective in a setting like school and with a population like students where more social norms are embedded in. (Valente et al, 2007). Though a number of successful projects have applied community based 
approach to prevent alcohol, there is a limited evidence to date for utilizing HPA to mobilize communities in which use the concept of empowerment to change behaviors. Most of the previous studies focused on improving knowledge while some studies focus on addressing mediating variables. Further these studies mostly rely on health education and distributing information, communication and education materials on individual basis. According to past studies human behavior is influenced by many other factors other than knowledge. Further, alcohol usage is determined based on the socio-cultural milieu in which it is used. This socio-cultural milieu determines the factors that contribute to the initiation and continuation of usage (Kuntsche et al, 2005).

Past studies stood with lack of proper theory and a LFW which could be used to explain gained changes. By contrast, this study conducted according to the HPP. Moreover according to the LFW, the acceptance on seven norms among students changed due to the sight of their own acceptance of norms and due to the questioning process of UCF of acceptance of norms. This empowerment concept through HPA is novel to Sri Lanka. In comparison, this is one of the first quasi experimental studies which explain the behavior of each single norm followed an intervention. Further studies are needed to follow up this study subjects to measure the impact, as the high acceptance of attractive image on alcohol, among the study subjects predicts the probability of initiate alcohol experiments in future (Samarasinghe, 2006a). Although students have initiated a change after the intervention, it was noted that some norms haven't change significantly. So, this finding will indicate a future research area.

\section{Strengthens and Limitations}

Since this study targets to see an effectiveness of a HP intervention it was not intended to generalize findings to average student population. Therefore we had a small sample size and not use a proper sampling technique thus this study consisted with 13-16 years and centralized around a school. So, this will hinder the reflections of average school environment. Other obstacles were discrepancies between our and organizational goals and obtaining time slots from the school time tables for the interventions. Within the limited time frame we had to measure short term impacts of the process.

\section{Conclusions}

Developed intervention model is successful in changing part of the selected social norms on attractive image on alcohol and amendments to intervention activities should be needed for non-changed norms.

\section{References}

Alcohol and Drug Information Centre, 2010, Trends in alcohol use Date of access 25/12/2017

http://adicsrilanka.org/wp-content/uploads/2017/06/Spopt-Survey_Alcohol-Report-July-2010.pdf

Borsari, B. and Carey, K.B., 2001, Peer influences on college drinking: A review of the research. Journal of substance abuse, 13(4), 391-424.

Carey, K.B., Scott-Sheldon, L.A., Carey, M.P. and DeMartini, K.S., 2007, Individual-level interventions to reduce college student drinking: A meta-analytic review. Addictive behaviors, 32(11), 2469-2494.

Conway, D.I., 2005, Alcohol consumption and the risk for disease. Evidence-based dentistry, 6(3), 76.

De Silva, V., Samarasinghe, D. and Gunawardena, N., 2009, Alcohol and tobacco use among males in two districts in Sri Lanka. Ceylon medical journal, 54(4).

Derges, J., Kidger, J., Fox, F., Campbell, R., Kaner, E. and Hickman, M., 2017, Alcohol screening and brief interventions for adults and young people in health and community-based settings: a qualitative systematic literature review. BMC public health, 17(1), 562.

Grant, B.F. and Dawson, D.A., 1997, Age at onset of alcohol use and its association with DSM-IV alcohol abuse and dependence: results from the National Longitudinal Alcohol Epidemiologic Survey. Journal of substance abuse, 9, 103-110. 
Harachi, T.W., Ayers, C.D., Hawkins, J.D., Catalano, R.F. and Cushing, J., 1996, Empowering communities to prevent adolescent substance abuse: Process evaluation results from a risk-and protection-focused community mobilization effort. Journal of Primary Prevention, 16(3), 233-254.

Hawkins, J.D., Catalano, R.F. and Miller, J.Y., 1992, Risk and protective factors for alcohol and other drug problems in adolescence and early adulthood: implications for substance abuse prevention. Psychological bulletin, 112(1), 64.

Jackson, M.C., Hastings, G., Wheeler, C., Eadie, D. and MacKintosh, A.M., 2000, Marketing alcohol to young people: implications for industry regulation and research policy. Addiction, 95(12s4), 597-608.

Jernigan, D.H. and World Health Organization, 2001. Global status report: alcohol and young people.

Kuntsche, E., Knibbe, R., Gmel, G. and Engels, R., 2005. Why do young people drink? A review of drinking motives. Clinical psychology review, 25(7), pp.841-861.

Mokdad, A.H., Forouzanfar, M.H., Daoud, F., Mokdad, A.A., El Bcheraoui, C., Moradi-Lakeh, M., Kyu, H.H., Barber, R.M., Wagner, J., Cercy, K. and Kravitz, H., 2016, Global burden of diseases, injuries, and risk factors for young people's health during 1990-2013: a systematic analysis for the Global Burden of Disease Study 2013. The Lancet, 387(10036), 2383-2401.

Perera, B. and Torabi, M., 2009, Motivations for alcohol use among men aged 16-30 years in Sri Lanka. International journal of environmental research and public health, 6(9), 2408-2416.

Peris, K, Guruge, D, Perera, M, Senarathne, L. 2013, Children's Health Country Programme: First Phase Programme Review 2010-2012. HaPAN/PLAN/Rajarata University of Sri Lanka.

Perry, C.L., Williams, C.L., Veblen-Mortenson, S., Toomey, T.L., Komro, K.A., Anstine, P.S., McGovern, P.G., Finnegan, J.R., Forster, J.L., Wagenaar, A.C. and Wolfson, M., 1996. Project Northland: outcomes of a communitywide alcohol use prevention program during early adolescence. American Journal of Public Health, 86(7), pp.956-965

Rehm, J., Mathers, C., Popova, S., Thavorncharoensap, M., Teerawattananon, Y. and Patra, J., 2009, Global burden of disease and injury and economic cost attributable to alcohol use and alcohol-use disorders. The Lancet, 373(9682), 2223-2233.

Samarasinghe D, 2006a, Reducing harm from use of alcohol: Community Responses. Date of access 12/11/201 www.searo.who.int/entity/mental_health/documents/929022276x.pdf?ua=1

Samarasinghe, D, Guruge, D, Ranasinghe, R, Amunigama, S, Fernando, F, Indawansa, S. 2011, Health Promotion Process. (Colombo: Sri Lanka: Ministry of Health)

Samarasinghe, D., 2006, Sri Lanka: alcohol now and then. Addiction, 101(5), .626-628.

Samarasinghe, D.S., Dissanayake, S.A.W. and Wijesinghe, C.P., 1987, Alcoholism in Sri Lanka: an epidemiological survey. Addiction, 82(10), 1149-1153.

Somatunga, L.C., Ratnayake, L.V.R., Wijesinghe, W.M.D.N.K., Yapa, Y.M.M.M. and Cooray, M.P.N.S., 2014, National alcohol use prevalence survey in Sri Lanka. Journal of the Postgraduate Institute of Medicine, 1.

Spoth, R.L., Redmond, C., Trudeau, L. and Shin, C., 2002, Longitudinal substance initiation outcomes for a universal preventive intervention combining family and school programs. Psychology of Addictive Behaviors, 16(2), 129.

Valente, T.W., Ritt-Olson, A., Stacy, A., Unger, J.B., Okamoto, J. and Sussman, S., 2007, Peer acceleration: effects of a social network tailored substance abuse prevention program among high-risk adolescents. Addiction, 102(11), 1804-1815.

Velleman, R., 2009, How do children and young people learn about alcohol: A major review of the literature for the Joseph Rowntree Foundation.

Whiteford, H.A., Degenhardt, L., Rehm, J., Baxter, A.J., Ferrari, A.J., Erskine, H.E., Charlson, F.J., Norman, R.E., Flaxman, A.D., Johns, N. and Burstein, R., 2013, Global burden of disease attributable to mental and substance use disorders: findings from the Global Burden of Disease Study 2010. The Lancet, 382(9904), 5751586.

World Health Organization, 2004. Global status report on alcohol Date of access 21/10/2017 www.who.int/substance_abuse/publications/global_status_report_2004_overview.pdf

World Health Organization. 2009, Milestones in Health Promotion- Statements from Global Conferences Date of access 12/02/2017 www.who.int/healthpromotion/Milestones_Health_Promotion_05022010.pdf. 
Sujith Jayarathna et al /A Community Based Health Promotion Intervention In Changing The.....

Yan, F.A., Beck, K.H., Howard, D., Shattuck, T.D. and Kerr, M.H., 2008, A structural model of alcohol use pathways among Latino youth. American Journal of Health Behavior, 32(2), 209-219 


\section{Appendix}

Table 1: Adolescent's basic socioeconomic and demographic data

\begin{tabular}{lll}
\hline $\begin{array}{l}\text { Socio-demographic } \\
\text { characteristic }\end{array}$ & $\begin{array}{l}\text { Intervention Group } \\
\text { Number (\%) (Total=90) }\end{array}$ & $\begin{array}{l}\text { Control Group } \\
\text { Number (\%) (Total=90) }\end{array}$ \\
\hline Gender & $50(44.4)$ & $55(61.1)$ \\
\hline Male & $40(55.5)$ & $35(38.9)$ \\
\hline Female & & \\
\hline Religion & & \\
\hline Buddhist & $05(94.4) 83(92.2)$ & $7(7.8)$ \\
\hline Other & & $51(56.7)$ \\
\hline Occupation of the father & $42(46.7)$ & $19(21.1)$ \\
\hline Farmer & $22(24.4)$ & $20(22.2)$ \\
\hline Forces & $26(28.9)$ & $04(12.5)$ \\
\hline Other(Teacher, Trade) & $05(14.3)$ & \\
\hline Other & & \\
\hline
\end{tabular}


Table 2: Prevalence of attractive image among students in pre evaluation

\begin{tabular}{|c|c|c|c|}
\hline Norm & $\begin{array}{l}\text { Intervention pre- } \\
\text { evaluation }(\%)\end{array}$ & Control pre-evaluation $(\%)$ & $\mathrm{P}$ value $*$ \\
\hline \multicolumn{4}{|c|}{ Majority of alcohol users feel it as a comfortable experience for body. } \\
\hline Agree & $56(62.2)$ & $47(52.2)$ & \multirow[t]{2}{*}{0.175} \\
\hline Disagree & $34(37.8)$ & $43(47.8)$ & \\
\hline \multicolumn{4}{|c|}{ Alcohol is a method of engaging with the new fashion } \\
\hline Agree & $48(53.8)$ & $53(58.9)$ & \multirow[t]{2}{*}{0.453} \\
\hline Disagree & $42(46.7)$ & $37(41.1)$ & \\
\hline \multicolumn{4}{|c|}{ Alcohol use is a behavior among majority of people in the society. } \\
\hline Agree & $53(58.9)$ & $52(57.8\}$ & \multirow[t]{2}{*}{0.880} \\
\hline Disagree & $37(41.1)$ & $38(42.2)$ & \\
\hline \multicolumn{4}{|c|}{ Alcohol is a good way to show rebelliousness } \\
\hline Agree & $47(52.2)$ & $49(54.4)$ & \multirow[t]{2}{*}{0.765} \\
\hline Disagree & $43(47.8)$ & $41(46.6)$ & \\
\hline \multicolumn{4}{|c|}{ After drinking alcohol it is normal to forget what is doing } \\
\hline Agree & $51(56.7)$ & $47(52.2)$ & \multirow[t]{2}{*}{0.549} \\
\hline Disagree & $39(43.3)$ & $43(47.8)$ & \\
\hline \multicolumn{4}{|c|}{ Behavior of a drunken person is totally due to the influence of alcohol. } \\
\hline Agree & $53(58.9)$ & $50(55.6)$ & \multirow[t]{2}{*}{0.651} \\
\hline Disagree & $37(41.1)$ & $40(44.4)$ & \\
\hline \multicolumn{4}{|c|}{ It is easy to threat others under the influence of alcohol } \\
\hline Agree & $58(64.4)$ & $51(56.7)$ & \multirow[t]{2}{*}{0.286} \\
\hline Disagree & $32(35.6)$ & $39(43.3)$ & \\
\hline \multicolumn{4}{|c|}{ When people drunk it is not suitable to discuss domestic matters. } \\
\hline Agree & $57(63.3)$ & $49(54.4)$ & \multirow[t]{2}{*}{0.226} \\
\hline Disagree & $33(36.7)$ & $41(45.6)$ & \\
\hline \multicolumn{4}{|c|}{ It is not need to care about the things done by the drunken person. } \\
\hline Agree & $60(66.7)$ & $58(64.4)$ & \multirow[t]{2}{*}{0.754} \\
\hline Disagree & $30(33.3)$ & $32(35.6)$ & \\
\hline \multicolumn{4}{|c|}{ By using alcohol people can become more violent. } \\
\hline Agree & $57(63.3)$ & $52(57.8)$ & \multirow[t]{2}{*}{0.446} \\
\hline Disagree & $33(36.7)$ & $38(42.2)$ & \\
\hline
\end{tabular}

\footnotetext{
*significant level $=0.05$
} 
Table 3: Changes in prevalence of attractive image in intervention group- Post evaluation

\begin{tabular}{|c|c|c|c|}
\hline Norm & $\begin{array}{l}\text { Intervention pre-evaluation } \\
(\%)\end{array}$ & $\begin{array}{l}\text { Intervention post - } \\
\text { evaluation }(\%)\end{array}$ & $\mathrm{P}$ value $*$ \\
\hline \multicolumn{4}{|c|}{ Majority of alcohol users feel it as comfortable experience for body. } \\
\hline Agree & $56(62.2)$ & $26(28.9)$ & \multirow[t]{2}{*}{0.000} \\
\hline Disagree & $34(37.8)$ & $64(71.1)$ & \\
\hline \multicolumn{4}{|c|}{ Alcohol is a method of engaging with the new fashion } \\
\hline Agree & $48(53.8)$ & $37(41.1)$ & \multirow[t]{2}{*}{0.101} \\
\hline Disagree & $42(46.7)$ & $53(58.9)$ & \\
\hline \multicolumn{4}{|c|}{ Alcohol use is a behavior among majority of people in the society. } \\
\hline Agree & $53(58.9)$ & $11(12.2)$ & \multirow[t]{2}{*}{0.000} \\
\hline Disagree & $37(41.1)$ & $79(87.8)$ & \\
\hline \multicolumn{4}{|c|}{ Alcohol is a good way to show rebelliousness } \\
\hline Agree & $47(52.2)$ & $38(42.2)$ & \multirow[t]{2}{*}{0.179} \\
\hline Disagree & $43(47.8)$ & $52(57.8)$ & \\
\hline \multicolumn{4}{|c|}{ After drinking alcohol it is normal to forget what is doing } \\
\hline Agree & $51(56.7)$ & $31(34.4)$ & \multirow[t]{2}{*}{0.003} \\
\hline Disagree & $39(43.3)$ & $59(65.6)$ & \\
\hline \multicolumn{4}{|c|}{ Behavior of a drunken person is totally due to the influence of alcohol. } \\
\hline Agree & $53(58.9)$ & $07(7.8)$ & \multirow[t]{2}{*}{0.000} \\
\hline Disagree & $37(41.1)$ & $83(92.2)$ & \\
\hline \multicolumn{4}{|c|}{ It is easy to threat others under the influence of alcohol } \\
\hline Agree & $58(64.4)$ & $53(58.9)$ & \multirow[t]{2}{*}{0.443} \\
\hline Disagree & $32(35.6)$ & $37(41.1)$ & \\
\hline \multicolumn{4}{|c|}{ When people drunk it is not suitable to discuss domestic matters. } \\
\hline Agree & $57(63.3)$ & $22(24.4)$ & \multirow[t]{2}{*}{0.000} \\
\hline Disagree & $33(36.7)$ & $68(75.6)$ & \\
\hline \multicolumn{4}{|c|}{ It is not need to care about the things done by the drunken person. } \\
\hline Agree & $60(66.7)$ & $21(23.3)$ & \multirow[t]{2}{*}{0.000} \\
\hline Disagree & $30(33.3)$ & $69(76.7)$ & \\
\hline \multicolumn{4}{|c|}{ By using alcohol people can become more violent. } \\
\hline Agree & $57(63.3)$ & $09(10.0)$ & \multirow[t]{2}{*}{0.000} \\
\hline Disagree & $33(36.7)$ & $81(90.0)$ & \\
\hline
\end{tabular}

*significant level $=0.05$ 
Sujith Jayarathna et al /A Community Based Health Promotion Intervention In Changing The.....

Table 4: Changes in prevalence of attractive image among students in control group- Post evaluation

\begin{tabular}{|c|c|c|c|}
\hline Norm & Control pre-evaluation (\%) & Control post-evaluation (\%) & $\mathrm{P}$ value $*$ \\
\hline \multicolumn{4}{|c|}{ Majority of alcohol users feel it as comfortable experience for body. } \\
\hline Agree & $47(52.2)$ & $45.0(50.0)$ & \multirow[b]{2}{*}{0.766} \\
\hline Disagree & $43(47.8)$ & $45.0(50.0)$ & \\
\hline \multicolumn{4}{|c|}{ Alcohol is a method of engaging with the new fashion } \\
\hline Agree & $53(58.9)$ & $56(62.2)$ & \multirow[b]{2}{*}{0.647} \\
\hline Disagree & $37(41.1)$ & $34(37.8)$ & \\
\hline \multicolumn{4}{|c|}{ Alcohol use is a behavior among majority of people in society. } \\
\hline Agree & $52(57.8)$ & $48(53.6)$ & \multirow[b]{2}{*}{0.549} \\
\hline Disagree & $38(42.2)$ & $42(46.7)$ & \\
\hline \multicolumn{4}{|c|}{ Alcohol is a good way to show rebelliousness } \\
\hline Agree & $49(54.4)$ & $49(54.4)$ & \multirow[b]{2}{*}{1.000} \\
\hline Disagree & $41(45.6)$ & $41(45.6)$ & \\
\hline \multicolumn{4}{|c|}{ After drinking alcohol it is normal to forget what is doing } \\
\hline Agree & $47(52.2)$ & $49(54.4)$ & \multirow[b]{2}{*}{0.765} \\
\hline Disagree & $43(47.8)$ & $41(45.6)$ & \\
\hline
\end{tabular}

Behavior of a drunken person is totally due to the influence of alcohol.

\begin{tabular}{llll}
\hline Agree & $50(55.6)$ & $51(56.7)$ & \multirow{2}{*}{0.881} \\
\cline { 1 - 3 } Disagree & $40(44.4)$ & $39(43.3)$ & \\
\cline { 1 - 2 } It is easy to threat others under the influence of alcohol & & 0.545 \\
\cline { 1 - 2 } Agree & $51(56.7)$ & $55(61.1)$ & \\
\cline { 1 - 2 } Disagree & $39(43.3)$ & $35(38.9)$ & \\
\hline
\end{tabular}

When people drunk it is not suitable to discuss domestic matters.

\begin{tabular}{llll}
\hline Agree & $49(54.4)$ & $48(53.3)$ & 0.881 \\
\cline { 1 - 2 } Disagree & $41(45.6)$ & $42(46.7)$ & \\
\hline
\end{tabular}

It is not need to care about things done by the drunken person.

\begin{tabular}{llll}
\hline Agree & $58(64.4)$ & $56(62.2)$ & 0.757 \\
\cline { 1 - 2 } Disagree & $32(35.6)$ & $34(37.8)$ & \\
\cline { 1 - 2 } \multicolumn{2}{l}{ By using alcohol people can become more violent. } & & 0.649 \\
\cline { 1 - 2 } Agree & $52(57.8)$ & $55(61.1)$ & \\
\hline Disagree & $38(42.2)$ & $35(38.9)$ & \\
\hline
\end{tabular}

\footnotetext{
*significant level $=0.05$
} 
Table 5: Changes in prevalence of attractive image among students in post evaluation in both intervention and control groups

\begin{tabular}{|c|c|c|c|}
\hline Norm & $\begin{array}{l}\text { Intervention post-evaluation } \\
(\%)\end{array}$ & Control post-evaluation $(\%)$ & $\mathrm{P}$ value $*$ \\
\hline \multicolumn{4}{|c|}{ Majority of alcohol users feel it as comfortable experience for body. } \\
\hline Agree & 26(28.9) & $45.0(50.0)$ & \multirow[b]{2}{*}{0.004} \\
\hline Disagree & $64(71.1)$ & $45.0(50.0)$ & \\
\hline \multicolumn{4}{|c|}{ Alcohol is a method of engaging with the new fashion } \\
\hline Agree & $37(41.1)$ & $56(62.2)$ & \multirow[t]{2}{*}{0.005} \\
\hline Disagree & $53(58.9)$ & $34(37.8)$ & \\
\hline \multicolumn{4}{|c|}{ Alcohol use is a behavior among majority of people in society. } \\
\hline Agree & $11(12.2)$ & $48(53.6)$ & \multirow[b]{2}{*}{0.000} \\
\hline Disagree & $79(87.8)$ & $42(46.7)$ & \\
\hline \multicolumn{4}{|c|}{ Alcohol is a good way to show rebelliousness } \\
\hline Agree & $38(42.2)$ & $49(54.4)$ & \multirow[b]{2}{*}{0.101} \\
\hline Disagree & $52(57.8)$ & $41(45.6)$ & \\
\hline
\end{tabular}

After drinking alcohol it is normal to forget what is doing

\begin{tabular}{|c|c|c|c|}
\hline Agree & $31(34.4)$ & $49(54.4)$ & \multirow[b]{2}{*}{0.007} \\
\hline Disagree & $59(65.6)$ & $41(45.6)$ & \\
\hline \multicolumn{4}{|c|}{ Behavior of a drunken person is totally due to the influence of alcohol. } \\
\hline Agree & $07(7.8)$ & $49(54.4)$ & \multirow[t]{2}{*}{0.000} \\
\hline Disagree & $83(92.2)$ & $41(45.6)$ & \\
\hline \multicolumn{4}{|c|}{ It is easy to threat others under the influence of alcohol } \\
\hline Agree & $53(58.9)$ & $55(61.1)$ & \multirow[t]{2}{*}{0.761} \\
\hline Disagree & $37(41.1)$ & $35(38.9)$ & \\
\hline
\end{tabular}

When people drunk it is not suitable to discuss domestic matters.

\begin{tabular}{|c|c|c|c|}
\hline Agree & $22(24.4)$ & $48(53.3)$ & 0.000 \\
\hline Disagree & $68(75.6)$ & $42(46.7)$ & \\
\hline \multicolumn{4}{|c|}{ It is not need to care about things done by the drunken person. } \\
\hline Agree & $21(23.3)$ & $56(62.2)$ & \multirow[t]{2}{*}{0.000} \\
\hline Disagree & $69(76.7)$ & $34(37.8)$ & \\
\hline \multicolumn{4}{|c|}{ By using alcohol people can become more violent. } \\
\hline Agree & $09(10.0)$ & $55(61.1)$ & \multirow[t]{2}{*}{0.000} \\
\hline Disagree & $81(90.0)$ & $35(38.9)$ & \\
\hline
\end{tabular}

$*_{\text {significant level }=0.05}$ 


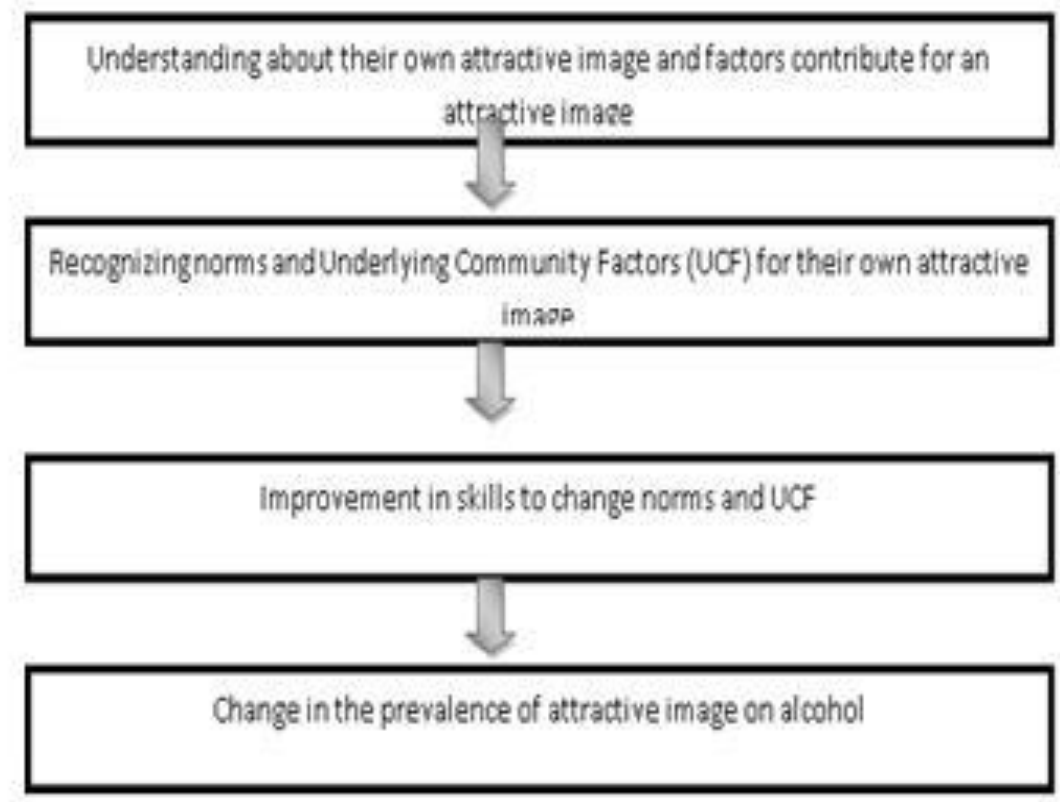

Figure 2- Norms selected for the intervention

\begin{tabular}{|l|}
\hline Majority of alcohol users feel it as comfortable experience for body. \\
\hline Alcohol is a method of engaging with the new fashion \\
\hline Alcohol use is a behavior among majority of people in society. \\
\hline Alcohol is a good way to show rebelliousness \\
\hline After drinking alcohol it is normal to forget what is doing \\
\hline Behavior of a drunken person is totally due to the influence of alcohol. \\
\hline It is easy to threat others under the influence of alcohol \\
\hline When people drunk it is not suitable to discuss domestic matters \\
\hline It is not need to care about things done by the drunken person \\
\hline By using alcohol people can become more violent. \\
\hline
\end{tabular}

